\title{
Characteristics, biosynthesis, decomposition, metabolism and functions of the garlic odour precursor, $S$-allyl-L-cysteine sulfoxide (Review)
}

\author{
YUSUKE YAMAGUCHI and HITOMI KUMAGAI \\ Department of Chemistry and Life Science, Nihon University, Fujisawa-shi 252-0880, Japan
}

Received September 30, 2019; Accepted November 6, 2019

DOI: $10.3892 /$ etm.2019.8385

\begin{abstract}
S-Allyl-L-cysteine sulfoxide (ACSO) is an odour precursor in garlic bulbs. One plausible pathway for the biosynthesis of ACSO involves $S$-2-carboxypropyl glutathione produced from glutathione and methacrylic acid via valine or from $\gamma$-glutamyl cysteine. The elimination of glycine and glutamic acid from $S$-2-carboxypropyl glutathione produces $S$-2-carboxypropyl cysteine, which is converted to $S$-allyl cysteine by decarboxylation and oxidation. $S$-Allyl cysteine is also biosynthesized via the elimination of glutamic acid from $\gamma$-glutamyl $S$-allyl cysteine by $\gamma$-glutamyl transpeptidase. The sulfur oxidation of $S$-allyl cysteine by flavin-containing monooxygenase forms ACSO. When cells are damaged by slicing or grating, ACSO in the cytoplasm or cytoplasmic vesicle is immediately converted to allylsulfenic acid, pyruvic acid, and ammonia by alliinase (C-S lyase), which is located in the vacuoles of vascular bundle sheath cells. Two molecules of allylsulfenic acid form diallyl thiosulfinate (allicin), which exhibits potent antimicrobial activity. Allicin eventually yields garlic odour compounds, such as diallyl disulfide (DADS) and diallyl trisulfide (DATS). Although these sulfides are known to exert various physiological functions, their strong odour limits their use in foods. On the other hand, ACSO is water-soluble and odourless and enhances sweet, salty, and umami tastes, characteristics of which are desirable for food additives. Upon consumption, ACSO is primarily absorbed from the small intestine in the intact form, but is also partly decomposed to allylsulfenic acid, pyruvic acid and ammonia. Allylsulfenic acid is then further converted to DADS and diallyl monosulfide (DAS). ACSO has numerous in vivo functions, such as the prevention of diabetes, myocardial ischaemia, hepatic injury, platelet aggregation and
\end{abstract}

Correspondence to: Professor Hitomi Kumagai, Department of Chemistry and Life Science, Nihon University, 1866 Kameino, Fujisawa-shi 252-0880, Japan

E-mail: kumagai.hitomi@nihon-u.ac.jp

Key words: garlic, odor precursor, $S$-allyl-L-cysteine sulfoxide, alliin, sulfide, biosynthesis, decomposition, metabolism, physiological function blood ethanol elevation. Although some of these effects may be attributed to its metabolites, ACSO itself contributes to many of these physiological functions.

\section{Contents}

1. Introduction

2. Characteristics of ACSO

3. Biosynthesis of ACSO

4. Content of ACSO and related compounds in garlic

5. Decomposition of ACSO and other sulfoxides

6. Metabolism of ACSO

7. Physiological functions of ACSO

8. Conclusions

\section{Introduction}

Garlic, which is well-known for its characteristic odour, has various biological functions, such as antioxidant and antimicrobial effects (1-3). It is also known to be able to prevent atherosclerosis (4), diabetes (5), cardiac hypertrophy (5), thrombosis, inflammation, hypertension and even cancer (6-9). Garlic itself does not have any potent odour; however, when garlic bulbs are cut or crushed, a sulfuric odour is instantaneously produced. The major odour precursor is $S$-(+)-allyl-L-cysteine sulfoxide ( $S$-2-propenyl cysteine sulfoxide; ACSO or alliin). When cells are damaged, ACSO is decomposed to produce garlic odour compounds, such as diallyl disulfide (di-2-propenyl disulfide; DADS) and diallyl trisulfide (di-2-propenyltrisulfide; DATS). These sulfides are the functional compounds that are responsible for the beneficial physiological activities of garlic (10); however, as they are lipophilic, volatile and have a strong odour, their use in foods is limited. On the other hand, ACSO is hydrophilic and odourless, rendering it useful as an additive in a wide range of foods. In light of recent findings, this review summarizes the characteristics and physiological functions of ACSO in vivo.

\section{Characteristics of ACSO}

ACSO is an amino acid that contains an amino group and carboxyl group in its structure with a molecular weight 
<smiles>NC(CCC(=O)N[C@@H](CS)C(=O)NCC(=O)O)C(=O)O</smiles>

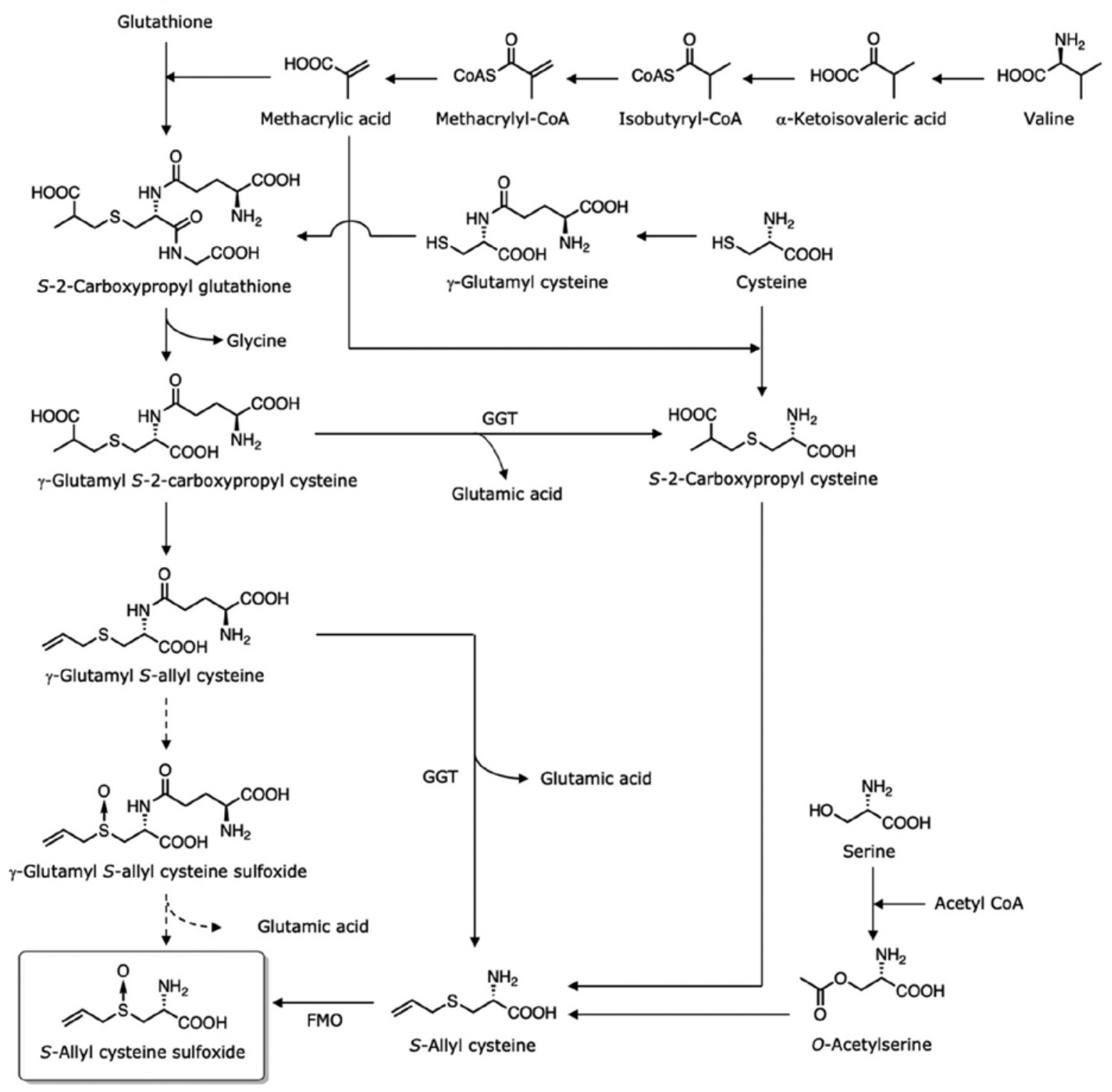

Figure 1. Putative pathways for the biosynthesis of ACSO. ACSO, S-allyl-L-cysteine sulfoxide.

of 177.22. According to the substance information in Chemical Abstracts (SciFinder Scholar), the physicochemical properties of ACSO are estimated. The density, $\mathrm{pKa}$, and boiling point of ACSO are predicted to be $1.354 \mathrm{~g} / \mathrm{ml}$ at $20^{\circ} \mathrm{C}, 1.88$ at $25^{\circ} \mathrm{C}$ and $416^{\circ} \mathrm{C}$, respectively, according to calculations of the Advanced Chemistry Development (ACD/Labs) software v11.02. Furthermore, the melting point is $165^{\circ} \mathrm{C}$ according to PhysProp data obtained from the Syracuse Research Corporation. The mass solubilities at $\mathrm{pH}$ 1, 2, 3-6, 7, 8, 9 and 10, as predicted by the ACD/Labs Software v11.02, are 120, 35, 27, 32, 76, 535 and $1,000 \mathrm{~g} / 1$, respectively, and ACSO is quite soluble in solutions above $\mathrm{pH}$ 9. ACSO itself is odourless and enhances sweet, salty and umami tastes (11). Therefore, ACSO may be one of the key components that produce a rich flavour in garlic-containing foods.

\section{Biosynthesis of ACSO}

The biosynthesis of ASCO is presented in Fig. 1. Although several biosynthetic pathways for ACSO have been proposed, its biosynthesis remains under debate (12-14). Tracing the radioactivity of labelled valine reveals that the radioactivity is located in the carboxypropyl group of $S$-2-carboxypropyl glutathione and $S$-2-carboxypropyl cysteine (15). $S$-2-Carboxypropyl glutathione is biosynthesized from glutathione (a tripeptide comprised of glycine, cysteine, and glutamic acid) with methacrylic acid produced from valine. However, two possible pathways forming $S$-2-carboxypropyl cysteine have been reported. One mechanism involves $\gamma$-glutamyl $S$-2-carboxypropyl cysteine produced from $S$-2-carboxypropyl glutathione via 


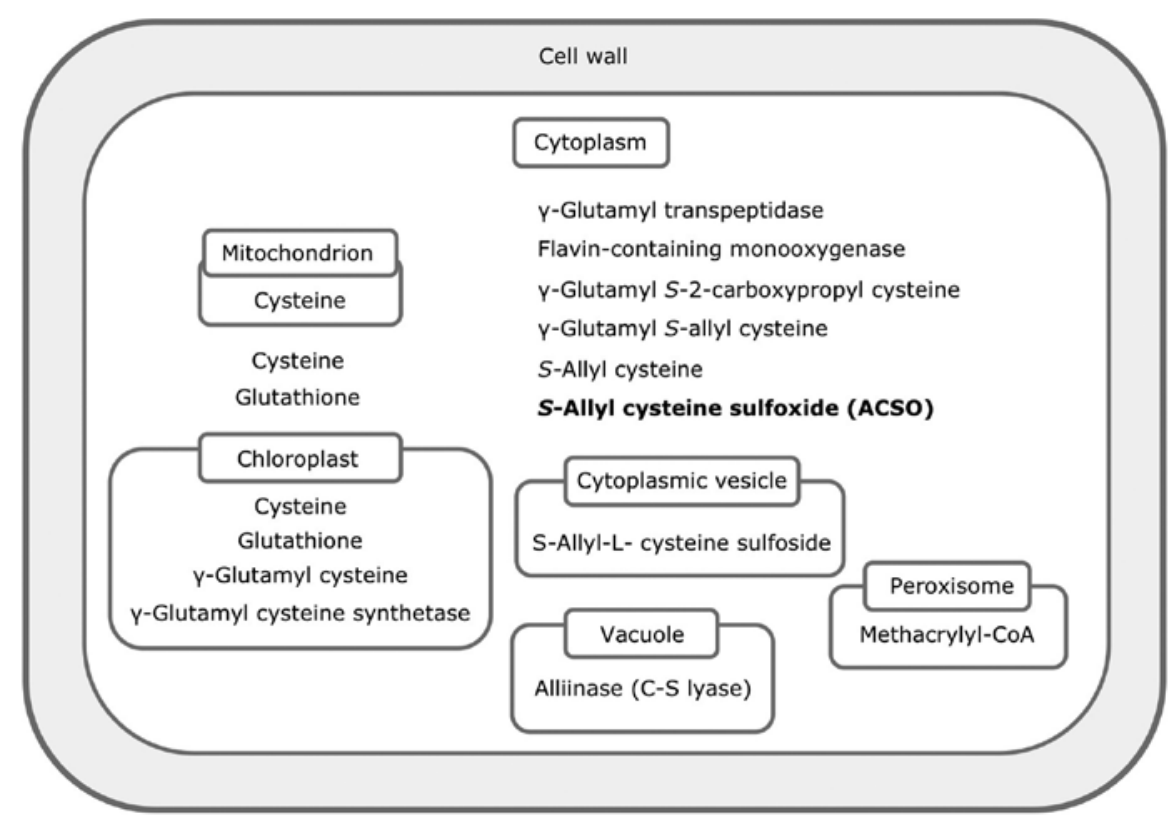

Figure 2. Localization of compounds and enzymes involved in biosynthesis of ACSO in a cell (13,17). ACSO, S-allyl-L-cysteine sulfoxide.

elimination of glycine, while the other involves generation from cysteine and methacrylic acid without passing through glutathione. These routes have also been proposed for the biosynthesis of trans-1-propenyl cysteine in onion (12). $S$-2-Carboxypropyl glutathione may also be produced from cysteine, as $\gamma$-glutamyl cysteine is detected in garlic (16). As decarboxylation and oxidation of the carboxypropyl group produce an allyl group (13), $\gamma$-glutamyl $S$-allyl cysteine can be produced from $\gamma$-glutamyl $S$-2-carboxypropyl cysteine, and $S$-allyl cysteine can be produced from $S$-2-carboxypropyl cysteine. The $S$-oxidation of $\gamma$-glutamyl $S$-allyl cysteine forms $\gamma$-glutamyl $S$-allyl cysteine sulfoxide, while that of $S$-allyl cysteine forms ACSO. Flavin-containing monooxygenase (FMO) in the cytosol is responsible for the $S$-oxidation in the biosynthesis of ACSO in the presence of nicotinamide adenine dinucleotide phosphate (NADPH) and flavin adenine dinucleotide (FAD) (17). On the other hand, the recombinant $\gamma$-glutamyl transpeptidase (GGT) prepared by cloning genes from garlic exhibits a high specificity for $\gamma$-glutamyl $S$-allyl cysteine, but not for $\gamma$-glutamyl $S$-allyl cysteine sulfoxide (18). Therefore, $S$-allyl cysteine produced from the deglutamylation of $\gamma$-glutamyl $S$-allyl cysteine forms ACSO via its $S$-oxidation, and the pathway via $\gamma$-glutamyl $S$-allyl cysteine sulfoxide to ACSO may not exist in garlic. The observations that ACSO can be produced with the addition of $S$-allyl cysteine in garlic callus (14) and that $S$-allyl cysteine is found in garlic $(19,20)$, also support this biosynthetic route from $S$-allyl cysteine to ACSO. As the addition of serine and allyl thiol produces ACSO (12), the pathway from serine via $S$-allyl cysteine to form ACSO is also probable.

The location of ACSO biosynthesis has not yet been convincingly identified. $\gamma$-Glutamyl peptides reside in the cytoplasm and cysteine sulfoxides in the cytoplasm or cytoplasmic vesicle, while $\gamma$-glutamyl cysteine resides in the chloroplast (13) (Fig. 2). As for the enzymes required for biosynthesis, $\gamma$-glutamyl cysteine synthetase is located in the chloroplast, and $\gamma$-glutamyl transpeptidase and flavin-containing monooxygenase are located in the cytoplasm (13).

\section{Content of ACSO and related compounds in garlic}

The majority of the organosulfur compounds in garlic are $\gamma$-glutamyl $S$-alkenyl cysteines and cysteine sulfoxides $(21,22)$, with ACSO being the major component. The ACSO content in fresh garlic is $3-14 \mathrm{mg} / \mathrm{g}$ fresh weight $(20,23,24)$ and $20-30$ $\mathrm{mg} / \mathrm{g}$ dry weight $(25,26)$. As regards other cysteine sulfoxides, the contents of $S$-methyl-L-cysteine sulfoxide (MCSO or methiin), trans-S-1-propenyl-L-cysteine sulfoxide (PeCSO or isoalliin) and cycloalliin are $0.5-2,0.1-1.2$ and $0.5-1.5 \mathrm{mg} / \mathrm{g}$ fresh weight, respectively (24). $\gamma$-L-Glutamyl- $S$-allyl-L-cysteine content in garlic bulbs is $2-7 \mathrm{mg} / \mathrm{g}$ fresh weight $(21,24)$ and $3-20 \mathrm{mg} / \mathrm{g}$ dry weight (26), while the $\gamma$-L-glutamyl-S-(trans-1propenyl)-L-cysteine content is $3-9 \mathrm{mg} / \mathrm{g}$ fresh weight $(21,24)$ and 5-15 mg/g dry weight (26). $\gamma$-L-Glutamyl- $S$-methyl-L-cyste ine is present at $0.1-0.4 \mathrm{mg} / \mathrm{g}$ fresh weight (24).

Sulfur fertilization increases the ACSO content in garlic cloves, while nitrogen fertilization decreases this content (27). Irrespective of the fertilization conditions, the ACSO content increases during storage at $20^{\circ} \mathrm{C}$ and decreases during storage at temperatures $>35^{\circ} \mathrm{C}(28)$. Drying at $60^{\circ} \mathrm{C}$ does not affect the ACSO content (29).

ACSO accumulates in leaves during early growth stages and translocates to the bulbs during bulb formation (30). Approximately $85 \%$ of ACSO is present in the bulbs, with approximately $12 \%$ in the leaves and $2 \%$ in the roots, while $\gamma$-glutamyl cysteines are found only in the bulbs (24). The $\gamma$-glutamyl-cysteine content in the bulbs increases a few weeks prior to harvest $(25,31)$. The ACSO content in the bulbs also begins to increase a few weeks prior to harvest $(25,31)$ but also further increases during the curing process (drying process after harvest for storage) (21). The content of ACSO in the leaves, however, remains relatively stable from 6 weeks to 1 week prior to harvest and subsequently decreases. 


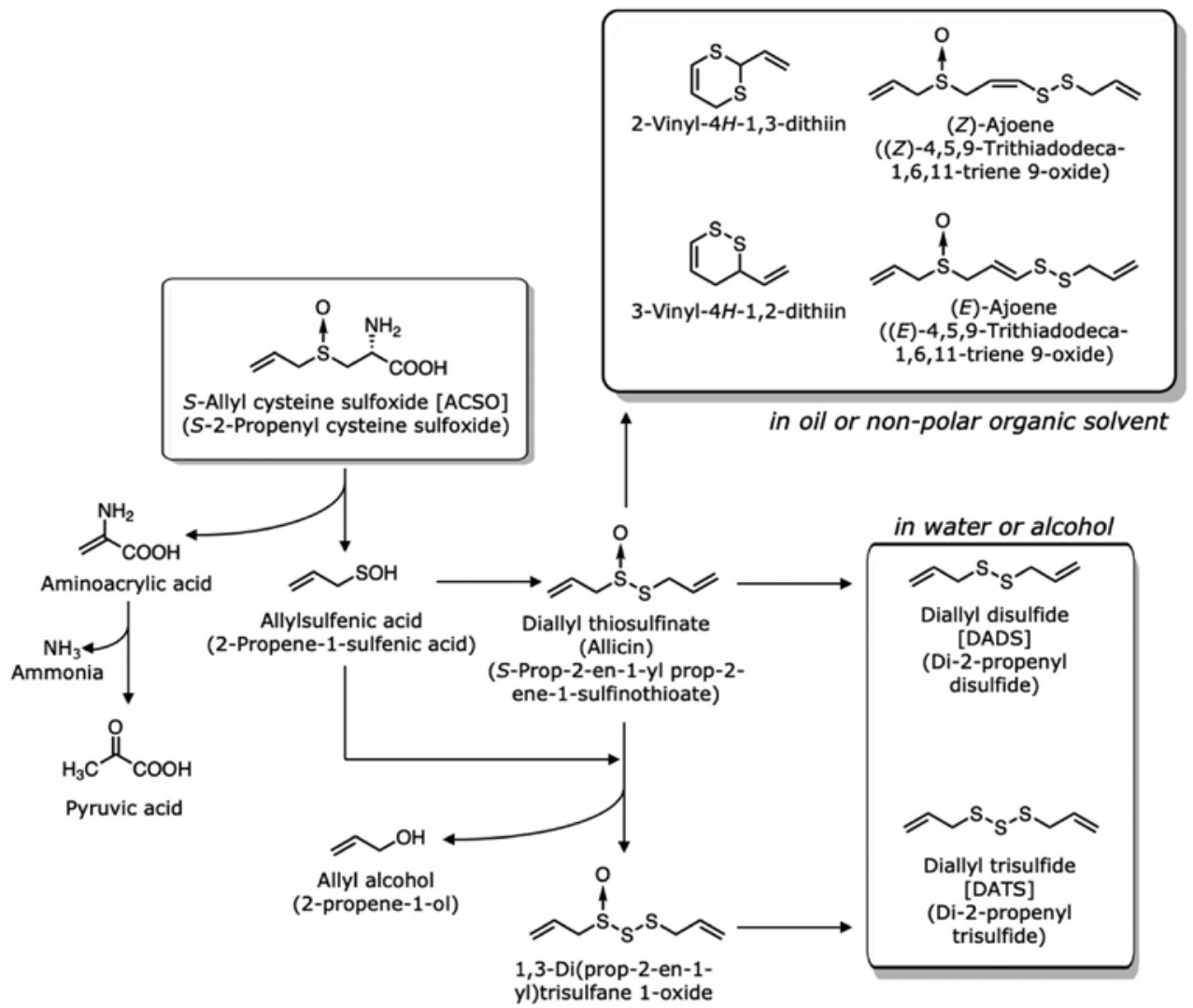

Figure 3. Formation of volatile compounds from ACSO. ACSO, $S$-allyl-L-cysteine sulfoxide.

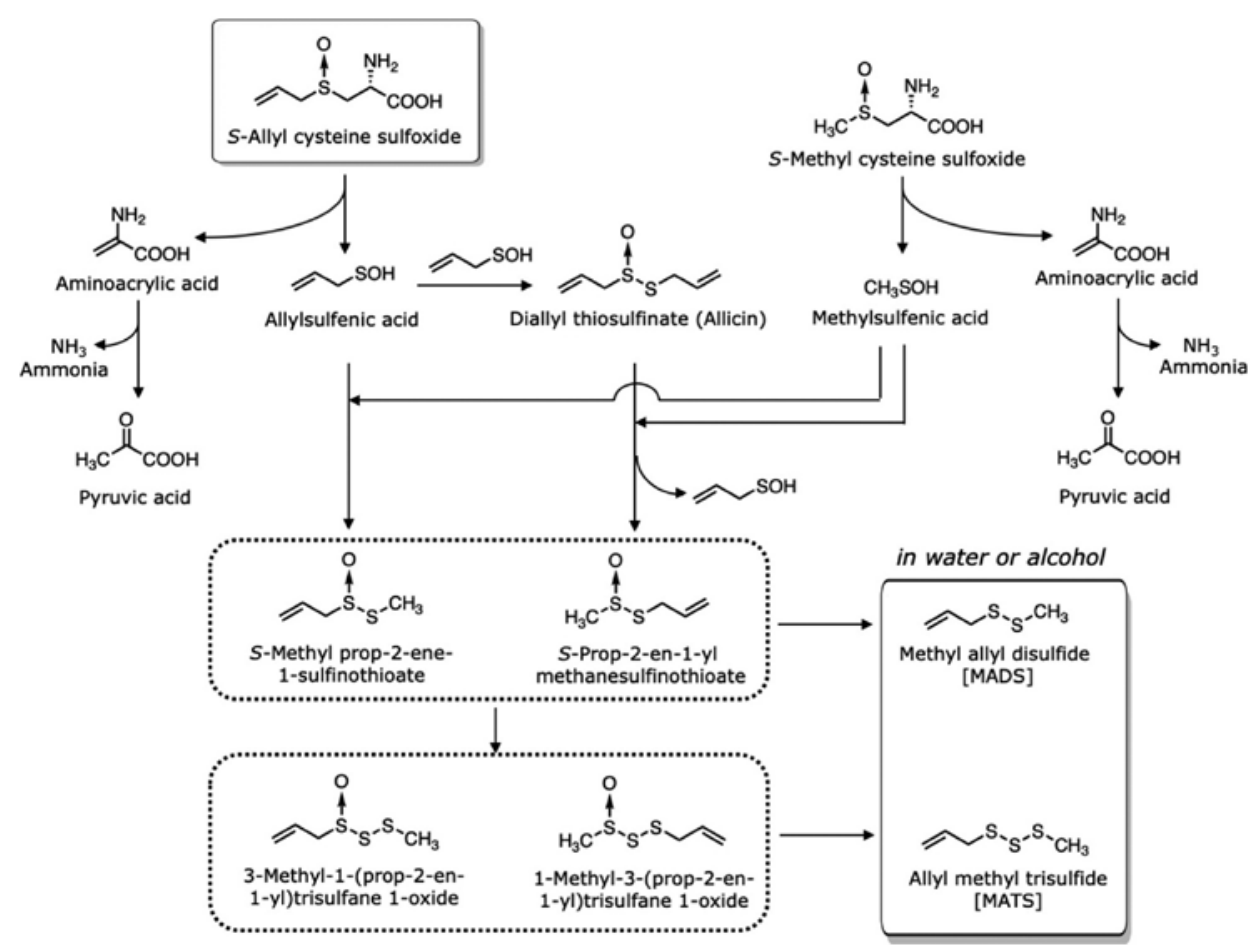

Figure 4. Formation of volatile compounds from ACSO and MCSO. ACSO, S-allyl-L-cysteine sulfoxide; MCSO, S-methyl-L-cysteine sulfoxide.

\section{Decomposition of ACSO and other sulfoxides}

The decomposition of ASCO and other sulfoxides is illustrated in Figs. 3 and 4. When garlic bulbs are sliced or ground during cooking, ACSO that resides in the cytoplasm or cytoplasmic vesicle of all cells (13) binds alliinase (C-S lyase; EC 4.4.1.4) that localizes in the vacuoles of vascular bundle sheath cells located around the veins or phloem (32). Alliinase belongs 
to a class 1 family of pyridoxal-5'-phosphate-dependent enzymes (2) and is a homodimeric glycoprotein, consisting of 448-amino-acid subunits with a molecular weight of 51,500 Da each (2). Two alliinase isozymes have been identified in garlic: One is specific for ACSO and PeCSO, and the other is specific for MCSO (22). ACSO is converted to allylsulfenic acid (2-propene-1-sulfenic acid; $\mathrm{CH}_{2}=\mathrm{CHCH} 2 \mathrm{SOH}$ ) (33) and aminoacrylic acid by alliinase. Aminoacrylic acid is then spontaneously converted to pyruvic acid and ammonia. Two molecules of allylsulfenic acid produce diallyl thiosulfinate ( $S$-prop-2-en-1-yl prop-2-ene-1-sulfinothioate; allicin), which exerts strong antimicrobial activity (34-37). The amount of allicin produced is approximately 0.1 to $7 \mathrm{mg} / \mathrm{g}$ fresh weight due to the abundance of ACSO in garlic $(7,38)$. The incorporation of an additional allylsulfenic acid and the removal of allyl alcohol yield 1,3-di(prop-2-en-1-yl)trisulfane 1-oxide. When garlic bulbs are homogenized in water or in an alcohol solution, DADS and DATS are mainly produced from the diallyl thiosulfinate and 1,3-di(prop-2-en-1-yl)trisulfane 1-oxide. Volatile oil obtained from garlic products by steam distillation contains DADS and DATS as the major components (38). These sulfides are known to have various physiological activities $(10,39)$; however, they are lipophilic and have a potent garlic odour. On the other hand, when garlic bulbs are homogenized in oil or in non-polar solvent, dithiins become dominant, 2-vinyl-4H-1,3-dithiin and 3-vinyl-4H-1,2-dithiin being about $0.4 \mathrm{mg} / \mathrm{g}$ and $0.17 \mathrm{mg} / \mathrm{g}$, respectively (38). Other components produced are $(E)$-ajoene $(0.07 \mathrm{mg} / \mathrm{g}),(Z)$-ajoene $(0.04 \mathrm{mg} / \mathrm{g})$, DATS $(0.07 \mathrm{mg} / \mathrm{g})$, methyl allyl trisulfide (MATS) $(0.06 \mathrm{mg} / \mathrm{g})$ and DADS $(0.03 \mathrm{mg} / \mathrm{g})$.

As MCSO is the second most abundant cysteine sulfoxide in garlic, representing approximately $10 \%$ of the total cysteine sulfoxides, the compounds produced from MCSO contribute to the composition of volatile oil. MCSO is also decomposed by alliinase when garlic is sliced or grated to yield methylsulfenic acid (Fig. 4). Allylsulfenic acid produced from ACSO and methylsulfenic acid produced from MCSO form $S$-methyl prop-2-ene-1-sulfinothioate and $S$-prop-2-en-1-yl methanesulfinothioate, the latter being twice as abundant at the former, though allicin accounts for $60-90 \%$ of the total thiosulfinates. The $S$-methyl prop-2-ene-1-sulfinothioate and $S$-prop-2-en-1-yl methanesulfinothioate form methyl allyl disulfide (MADS) and MATS. Importantly, the ratio of allyl groups and methyl groups in total thiosulfinates almost directly coincides with that in total $S$-alk(en)yl-L-cysteine sulfoxides in garlic (40). Among the sulfides, DATS $(0.8-1.1 \mathrm{mg} / \mathrm{g})$ and DADS (0.5-1 mg/g) are the most abundant, with MATS (0.2-0.7 $\mathrm{mg} / \mathrm{g})$ and MADS (0.08-0.5 mg/g) as the next most abundant. Dimethyl trisulfide (DMTS; 0.01-0.1 mg/g) and dimethyl disulfide (DMDS; 0.001-0.06 mg/g) occur in smaller quantities.

\section{Metabolism of ACSO}

The metabolism of ASCO is illustrated in Fig. 5. When $10 \mathrm{ml}$ of $100 \mathrm{mM} \mathrm{ACSO} / \mathrm{kg}$ body weight is injected into the ligated loop of the small intestine of rats, both ACSO and pyruvic-acid concentrations in the portal vein increase to approximately 4 and $0.2 \mathrm{mM}$, respectively, after $30 \mathrm{~min}$ (41), indicating that ACSO is mostly absorbed from the small intestine into the blood in the intact form; however, it is also partly converted to allylsulfenic acid, pyruvic acid and ammonia. In addition, mixing ACSO with crude proteins extracted from the small intestine of rats yields DADS and DAS as volatile compounds (41), supporting the assumption that ACSO is decomposed to allylsulfenic acid and two molecules of allylsulfenic acid produce DADS and DAS via allicin. Therefore, ACSO may follow the same fate as allicin and DADS in the body. When garlic oil is consumed, DADS, DAS and DMDS are detected in urine (42). When garlic extract is consumed, $N$-acetyl- $S$-allyl-L-cysteine (allylmercapturic acid) is identified in urine $(43,44)$. $N$-Acetyl-L-cysteine (mercapturic acid; MA) conjugates are commonly formed from glutathione conjugates. The glutathione conjugates are first transformed into L-cysteine conjugates via the elimination of glutamic acid by $\gamma$-glutamyl transpeptidase and glycine by cysteinylglycinase. Subsequently, L-cysteine conjugates are $N$-acetylated by cysteine-S-conjugate $N$-acetyltransferase to form MA conjugates (43). Allicin reacts with glutathione to produce $S$-allyl-mercaptoglutathione or with L-cysteine to produce $S$-allyl-mercaptocysteine in vivo (45). DADS undergoes nucleophilic substitution at the $\alpha$-carbon in a reaction with glutathione to yield $S$-allyl-glutathione and allyl perthiol. This $S$-allyl-glutathione is then converted to $S$-allyl cysteine by $\gamma$-glutamyl transpeptidase and cysteinylglycinase. The $S$-allyl cysteine is further transformed into $N$-acetyl- $S$-allyl-L-cysteine via $N$-acetylation by the cysteine-Sconjugate $N$-acetyltransferase (46).

\section{Physiological functions of ACSO}

Orally administered ACSO ameliorates the diabetic condition $(47,48)$. When diabetes is induced in rats by an injection of alloxan monohydrate, fasting blood glucose levels are reduced, and insulin secretion is increased by the daily oral administration of $200 \mathrm{mg} \mathrm{ACSO} / \mathrm{kg}$ body weight. In addition, orally administered ACSO reduces the generation of reactive aldehydes produced by lipid peroxidation, increasing catalase activity and glutathione content (47). Similar effects have been observed in mice with diet-induced obesity (DIO) (48). When these mice are fed a high-fat (60\% kcal from fat) diet for 8 weeks and provided with water containing $0.1 \mathrm{mg} \mathrm{ACSO} / \mathrm{ml}$ for a further 8 weeks, glucose homeostasis and insulin sensitivity are enhanced. The increase in blood glucose levels following the injection of glucose is suppressed, and the decrease in blood glucose level following the injection of insulin is promoted. In addition, ACSO administration improves the lipid profile and liver functions of the mice with DIO. ACSO treatment reduces the levels of triglycerides, low-density lipoprotein and non-esterized free fatty acid. It also decreases the activities of aspartate aminotransferase and alkaline phosphatase, and the levels of total protein and albumin in the blood (48).

Furthermore, ACSO has been shown to prevent myocardial ischaemia induced by isoproterenol in rats (49). When 40 or $80 \mathrm{mg} \mathrm{ACSO} / \mathrm{kg}$ body weight is administered to rats for 5 weeks, the increase in the activities of creatine kinase, lactate dehydrogenase, aspartate transaminase and alanine transferase in serum, and their decrease in the heart due to the induction of myocardial ischaemia are both suppressed. In addition, ACSO administration suppresses the increase in 3-hydroxy 3-methyl glutaryl coenzyme A (HMG CoA) 


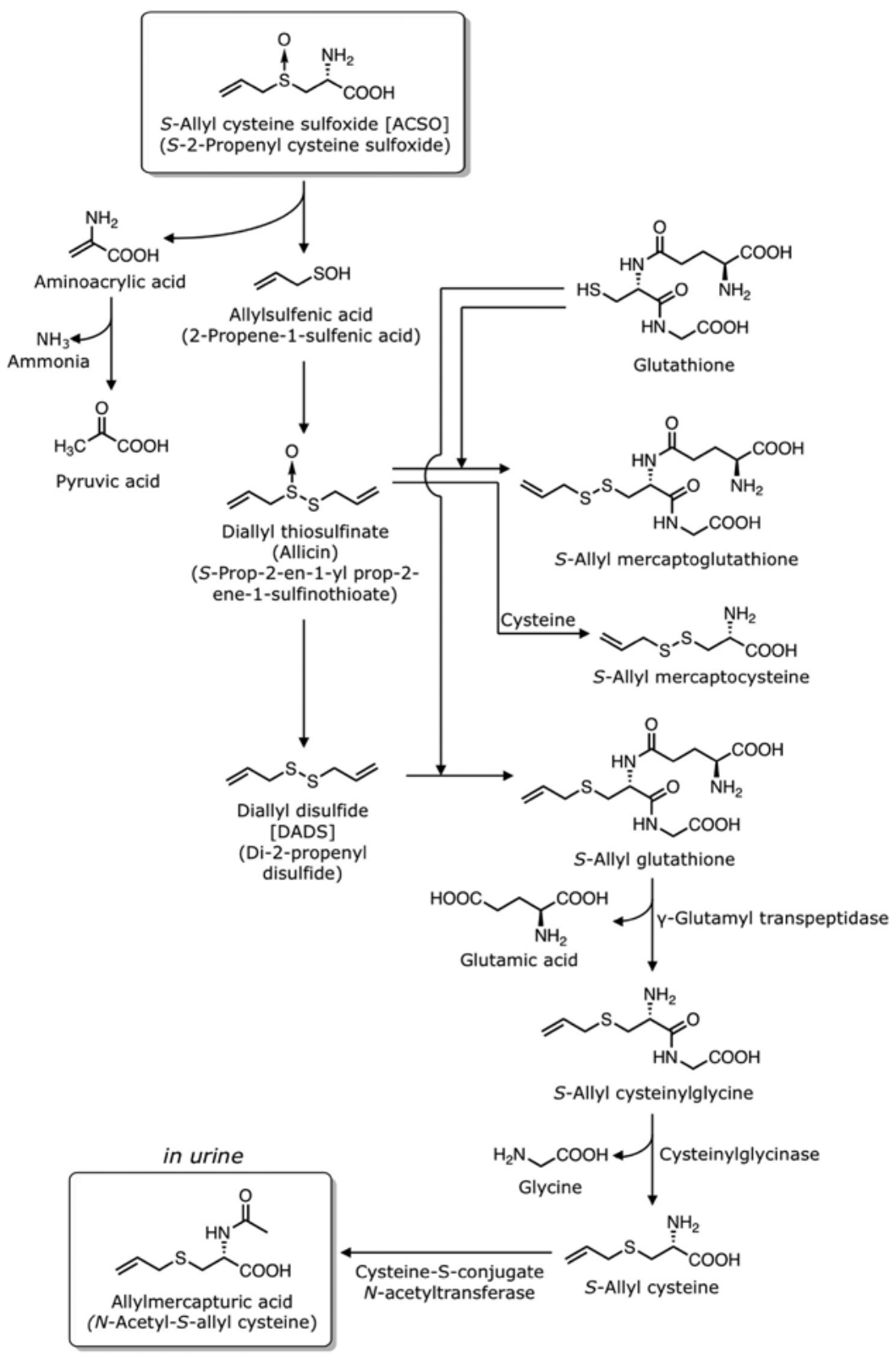

Figure 5. Putative pathways for metabolism of ACSO. ACSO, S-allyl-L-cysteine sulfoxide.

reductase activity in the liver and the decrease in lecithin cholesterol acyl transferase activity in the liver and heart in these isoproterenol-treated rats (49). The increase in the levels of plasma thiobarbituric acid reactive substances and hydroperoxide in mice with myocardial-ischaemia-induced is also suppressed by ACSO administration.

ACSO has also been shown to suppress oxidative stress in rats with carbon tetrachloride $\left(\mathrm{CCl}_{4}\right)$-induced hepatic injury (41). In rats with hepatic injury, following the oral administration of $50 \mu \mathrm{mol}$ ACSO for 7 days, the increased aspartate transaminase, alanine transaminase and lactate dehydrogenase activities as well as the amount of thiobarbituric acid reactive substances are suppressed. In addition, the decrease in glutathione levels and the activities of glutathione $S$-transferase and glutathione peroxidase are also suppressed. These observations indicate that ACSO prevents hepatic injury by enhancing the activities of phase II detoxifying enzymes and reducing oxidative stress. As MCSO, $S$-ethyl-L-cysteine sulfoxide (ECSO) and $S$-allyl-L-cysteine (ACS) are not effective for the prevention of hepatic injury, the allyl and sulfoxide groups in ACSO are essential for this preventive effect. Moreover, ACSO promotes nuclear factor erythroid 2-related factor 2 (Nrf2) nuclear translocation in HepG2 cells, leading to the induction of antioxidant and detoxifying enzymes, and contributing to these preventive effects (41).

In garlic, some of the sulfides, such as MATS and DMTS, exhibit inhibitory activity against platelet aggregation in vitro (50). As thrombosis is triggered by platelet aggregation, these sulfides may be the factors responsible for the prevention of thrombosis following garlic consumption. The administration of ACSO to rats, however, results in greater inhibitory activity against platelet aggregation than DADS (51). The effect of ACSO is most potent at a dosage of $10 \mathrm{mg} / \mathrm{kg}$ body weight, and the duration of the effect persists for 16-24 h 
following administration. Although DADS is produced during the absorption of ACSO from the small intestine (41), the functional component is assumed to be different, suggesting the in vivo production of potent ACSO metabolites that confer inhibitory activity against platelet aggregation.

Finally, ACSO suppresses the increase in blood ethanol concentration following the oral administration of ethanol and ACSO together (52). Although the supply of $\mathrm{NAD}^{+}$is the rate-limiting factor for the metabolism of ethanol to acetaldehyde, and $\mathrm{NAD}^{+}$is produced from NADH during the conversion of pyruvic acid to lactic acid by lactate dehydrogenase, pyruvate production during the absorption of ACSO from the small intestine is not responsible for this suppressive effect on blood ethanol elevation. The administration of pyruvic acid at levels equivalent to those of ACSO does not exert the suppressive effect on blood ethanol elevation. The mechanisms underlying the reduction in blood ethanol concentrations by ACSO involve the promotion of ethanol metabolism in the liver and the suppression of ethanol absorption from the gut (52). Specifically, ACSO induces the activities of alcohol dehydrogenase, which converts ethanol into acetaldehyde, and aldehyde dehydrogenase, which converts acetaldehyde into acetic acid. In addition, the injection of ACSO into the ligated stomach or small intestine together with ethanol results in the suppression of the increase in ethanol concentration in the portal vein, indicating overall suppression of ethanol absorption. Garlic extract rich in ACSO (Garlic-H) exhibits an effect similar to ACSO itself, while garlic extract that does not contain ACSO (Garlic-N) exerts less-potent effects compared to Garlic-H (52).

\section{Conclusions}

On the whole, as discussed in this review article, the physiological functions of ACSO are extensive and can be applied to promote human health. As ACSO is water-soluble and odourless and enhances taste, the addition of this garlic component to food products will provide both a rich flavour and may confer numerous health benefits.

\section{Acknowledgements}

Not applicable.

\section{Funding}

No funding was received.

\section{Availability of data and materials}

Not applicable.

\section{Authors' contributions}

YY and HK conceived and designed this review article and wrote the manuscript. Both authors have read and approved the final manuscript.

\section{Ethics approval and consent to participate}

Not applicable.

\section{Patient consent for publication}

Not applicable.

\section{Competing interests}

The authors declare that they have no competing interests.

\section{References}

1. Goncagul G and Ayaz E: Antimicrobial effect of garlic (Allium sativum) and traditional medicine. J Anim Vet Adv 9: 1-4, 2010.

2. Touloupakis E and Ghanotakis DF: Nutraceutical use of garlic sulfur-containing compounds. Adv Exp Med Biol 698: 110-121, 2010.

3. Rahman MS, Al-Sheibani HI, Al-Riziqi MH, Mothershaw A, Guizani N and Bengtsson G: Assesment of the anti-microbial activity of dried garlic powders produced by different methods of drying. Int J Food Prop 9: 503-513, 2006.

4. Durak I, Aytaç B, Atmaca Y, Devrim E, Avci A, Erol C and Oral D: Effects of garlic extract consumption on plasma and erythrocyte antioxidant parameters in atherosclerotic patients. Life Sci 75: 1959-1966, 2004

5. Padiya R, Chowdhury D, Borkar R, Srinivas R, Pal Bhadra M and Banerjee SK: Garlic attenuates cardiac oxidative stress via activation of PI3K/AKT/Nrf2-Keap1 pathway in fructose-fed diabetic rat. PLoS One 9: e94228, 2014.

6. Bongiorno PB, Fratellone PM and LoGiudice P: Potential health benefits of garlic (Allium sativum): A narrative review. J Complement Integr Med 5: 1-26, 2008.

7. Rose P, Whiteman M, Moore PK and Zhu YZ: Bioactive $S$-alk(en)yl cysteine sulfoxide metabolites in the genus Allium: The chemistry of potential therapeutic agents. Nat Prod Rep 22: 351-368, 2005.

8. Zawistowski J, Kopec A, Jedrszczyk E, Francik R and Bystrowska B: Garlic grown from air bulbils and its potential health benefits. ACS Symp Ser 1286: 315-328, 2018.

9. Mithen R: Sulphur-containing compounds. In: Plant secondary metabolites: occurrence, structure and role in the human diet. Crozier A, Clifford N and Ashida H (eds). Blackwell Publishing, Hoboken, NJ, pp25-46, 2006.

10. Palani S, Joseph NM, Tegene Y and Zacharia A: Medical properties of garlic - A concise review. Curr Res Pharm Sci 4: 92-98, 2014.

11. Ueda Y,Sakaguchi M, Hirayama K, Miyajima R and Kimizuka A: Characteristic flavor constituents in water extract of garlic. Agric Biol Chem 54: 163-169, 1990.

12. Granroth B: Biosynthesis and decomposition of cysteine derivatives in onion and other Allium species. Ann Acad Sci Fenn, Ser A2. Chem 154: 1-71, 1970.

13. Jones MG, Hughes J, Tregova A, Milne J, Tomsett AB and Collin HA: Biosynthesis of the flavour precursors of onion and garlic. J Exp Bot 55: 1903-1918, 2004.

14. Hughes J, Tregova A, Tomsett AB, Jones MG, Cosstick R and Collin HA: Synthesis of the flavour precursor, alliin, in garlic tissue cultures. Phy tochemistry 66: 187-194, 2005.

15. Suzuki T, Sugii M and Kakimoto T: Metabolic incorporation of L-valine- $\left[{ }^{14} \mathrm{C}\right]$ into $S$-(2-carboxypropyl) glutathione and $S$-(2-carboxypropyl) cysteine in garlic. Chem Pharm Bull (Tokyo) 10: 328-331, 1962.

16. Lancaster JE and Shaw ML: $\gamma$-Glutamyl peptides in the biosynthesis of $S$-alk(en)yl-L-cysteine sulfoxides (flavor precursors) in Allium. Phytochemistry 28: 455-460, 1989.

17. Yoshimoto N, Onuma M, Mizuno S, Sugino Y, Nakabayashi R, Imai S, Tsuneyoshi T, Sumi S and Saito K: Identification of a flavin-containing $S$-oxygenating monooxygenase involved in alliin biosynthesis in garlic. Plant J 83: 941-951, 2015.

18. Yoshimoto N, Yabe A, Sugino Y, Murakami S, Sai-Ngam N, Sumi S, Tsuneyoshi T and Saito K: Garlic $\gamma$-glutamyl transpeptidases that catalyze deglutamylation of biosynthetic intermediate of alliin. Front Plant Sci 5: 758, 2015.

19. Suzuki T, Sugii M, Kakimoto T and Tsuboi N: Isolation of (-)-S-allyl-L-cysteine from garlic. Chem Pharm Bull (Tokyo) 9: 251-252, 1961 .

20. Ziegler SJ and Sticher O: HPLC of $S$-alk(en)yl-L-cysteine derivatives in garlic including quantitative determination of (+)-S-allyl-L-cysteine sulfoxide (alliin). Planta Med 55: 372-378, 1989. 
21. Lawson LD, Wang Z-Y and Hughes BG: $\gamma$-Glutamyl$S$-alkylcysteines in garlic and other Allium spp.: Precursors of age-dependent trans-1-propenyl thiosulfinates. J Nat Prod 54: 436-444, 1991.

22. Farooqui AA and Farooqui T (eds): Garlic and its effects in neurological disorders. In: Neuroprotective effects of phytochemicals in neurological disorders. John Wiley \& Sons, Hoboken, NJ, pp113-131, 2017.

23. Hirata S, Abdelrahman M, Yamauchi N and Shigyo M: Characteristics of chemical components in genetic resources of garlic Allium sativum collected from all over the world. Genet Resour Crop Evol 63: 35-45, 2016.

24. Lawson LD: Garlic: A review of its medicinal effects and indicated active compounds. ACS Symp Ser 691: 176-209, 1998.

25. Ueda Y, Kawajiri H, Miyamura N and Miyajima R: Content of some sulfur-containing components and free amino acids in various strains of garlic. Nippon Shokuhin Kogyo Gakkaishi (J Jpn Soc Food Sci Technol) 38: 429-434, 1991.

26. Mütsch-Eckner M, Sticher O and Meier B: Reversed-phase high-performance liquid chromatography of $S$-alk(en)yl-L-cysteine derivatives in Allium sativum including the determination of (+)-S-allyl-L-cysteine sulphoxide, $\gamma$-L-glutamyl- $S$-allyl-L-cysteine and $\gamma$-L-glutamyl-S-(trans-1-propenyl)-L-cysteine. J Chromatogr A 625: 183-190, 1992.

27. Bloem E, Haneklaus S and Schnug E: Storage life of field-grown garlic bulbs (Allium sativum L.) as influenced by nitrogen and sulfur fertilization. J Agric Food Chem 59: 4442-4447, 2011.

28. Yamazaki Y and Okuno T: Accumulation of $S$-allyl-L-cysteine in garlic bulbs by warming. Nippon Shokuhin Kagaku Kogaku Kaishi 55: 410-415, 2008.

29. Rahman MS: Allicin and other functional active components in garlic: Health benefits and bioavailability. Int J Food Prop 10: 245-268, 2007.

30. Martins N, Petropoulos S and Ferreira ICFR: Chemical composition and bioactive compounds of garlic (Allium sativum L.) as affected by pre- and post-harvest conditions: A review. Food Chem 211: 41-50, 2016.

31. Matsuura $\mathrm{H}$, Inagaki $\mathrm{M}$, Maeshige $\mathrm{K}$, Ide $\mathrm{N}$, Kajimura $\mathrm{Y}$ and Itakura Y: Changes in contents of $\gamma$-glutamyl peptides and fructan during growth of Allium sativum. Planta Med 62: 70-71, 1996.

32. Ellmore GS and Feldberg RS: Allin lyase localization in bundle sheaths of the garlic clove (Allium sativum). Am J Bot 81: 89-94, 1994.

33. Penn RE, Block E and Revelle LK: Flash vacuum pyrolysis studies. 5. Methanesulfenic acid. J Am Chem Soc 100: 3622-3623, 1978.

34. Cavallito CJ, Buck JS and Suter CM: Allicin, the antibacterial principle of Allium sativum. II. Determination of the chemical structure. J Am Chem Soc 66: 1952-1954, 1944.

35. Borlinghaus J, Albrecht F, Gruhlke MC, Nwachukwu ID and Slusarenko AJ: Allicin: Chemistry and biological properties. Molecules 19: 12591-12618, 2014.

36. Choi MK: CHae K-Y, Lee J-Y and Kyung KH: Antimicrobial activity of chemical substances derived from $S$-alk(en)yl-L-cysteine sulfoxide (alliin) in garlic, Allium sativum L. Food Sci Biotechnol 16: $1-7,2007$.

37. Rabinkov A, Miron T, Konstantinovski L, Wilchek M, Mirelman D and Weiner L: The mode of action of allicin: Trapping of radicals and interaction with thiol containing proteins. Biochim Biophys Acta 1379: 233-244, 1998.
38. Lawson LD, Wang ZJ and Hughes BG: Identification and HPLC quantitation of the sulfides and dialk(en)yl thiosulfinates in commercial garlic products. Planta Med 57: 363-370, 1991.

39. Singh VK and Singh DK: Pharmacological effects of garlic (Allium sativum L.). Ann Rev Biomed Sci 10: 6-26, 2008.

40. BlockE, Naganathan S,Putman D and Zhao SH: Allium chemistry: HPLC analysis of thiosulfinates from onion, garlic, wild garlic (ramsoms), leek, scallion, shallot, elephant (great-headed) garlic, chive, and Chinese chive. Uniquely high allyl to methyl ratios in some garlic samples. J Agric Food Chem 40: 2418-2430, 1992.

41. Yamaguchi Y, Honma R, Yazaki T, Shibuya T, Sakaguchi T, Uto-Kondo $\mathrm{H}$ and Kumagai H: Sulfuric odor precursor $S$-allyl-L-cysteine sulfoxide in garlic induces detoxifying enzymes and prevents hepatic injury. Antioxidants 8: 385, 2019.

42. Bartzatt R, Blum D and Nagel D: Isolation of Garlic Derived Sulfur Compounds from Urine. Anal Lett 25: 1217-1224, 1992.

43. de Rooij BM, Boogaard PJ, Rijksen DA, Commandeur JN and Vermeulen NP: Urinary excretion of $N$-acetyl-S-allyl-L-cysteine upon garlic consumption by human volunteers. Arch Toxicol 70: 635-639, 1996.

44. Jandke J and Spiteller G: Unusual conjugates in biological profiles originating from consumption of onions and garlic. J Chromatogr A 421: 1-8, 1987.

45. Trio PZ, You S, He X, He J, Sakao K and Hou D-X: Chemopreventive functions and molecular mechanisms of garlic organosulfur compounds. Food Funct 5: 833-844, 2014.

46. Verhagen H, Hageman GJ, Rauma A-L, Versluis-de Haan G, van Herwijnen MHM, de Groot J, Törrönen R and Mykkänen H: Biomonitoring the intake of garlic via urinary excretion of allyl mercapturic acid. Br J Nutr 86 (Suppl 1): S111-S114, 2001.

47. Augusti KT and Sheela CG: Antiperoxide effect of $S$-allyl cysteine sulfoxide, an insulin secretagogue, in diabetic rats. Experientia 52: 115-120, 1996.

48. Zhai B, Zhang C, Sheng Y, Zhao C, He X, Xu W, Huang K and Luo Y: Hypoglycemic and hypolipidemic effect of $S$-allyl-cysteine sulfoxide (alliin) in DIO mice. Sci Rep 8: 3527, 2018.

49. Sangeetha T and Darlin Quine S: Preventive effect of $S$-allyl cysteine sulphoxide (Alliin) on mitochondrial dysfunction in normal and isoproterenol induced cardiotoxicity in male Wistar rats: A histopathological study. Mol Cell Biochem 328: 1-8, 2009.

50. Nishimura $\mathrm{H}$ and Ariga T: Vinyldithiins in garlic and Japanese domestic Allium (A. victorialis). CS Symp Ser 546: 128-143, 1993.

51. Akao M, Shibuya T, Shimada S, Sakurai H and Kumagai H: In vivo production of bioactive compounds from $S$-allyl-L-cysteine sulfoxide, garlic odor precursor, that inhibit platelet aggregation. J Clin Biochem Nutr (Suppl 43): 1-3, 2008.

52. Uto-Kondo H, Hase A, Yamaguchi Y, Sakurai A, Akao M, Saito T and Kumagai H: S-Allyl-L-cysteine sulfoxide, a garlic odor precursor, suppresses elevation in blood ethanol concentration by accelerating ethanol metabolism and preventing ethanol absorption from gut. Biosci Biotechnol Biochem 82: 724-731, 2018.

This work is licensed under a Creative Commons Attribution-NonCommercial-NoDerivatives 4.0 International (CC BY-NC-ND 4.0) License. 